\title{
Experimental in vivo and in vitro treatment with a new histone deacetylase inhibitor belinostat inhibits the growth of pancreatic cancer
}

Dmitriy I Dovzhanskiy', Stefanie M Arnold', Thilo Hackert ${ }^{1}$, Ina Oehme², Olaf Witt ${ }^{2,3}$, Klaus Felix', Nathalia Giese ${ }^{1}$ and Jens Werner ${ }^{1 *}$

\begin{abstract}
Background: Treatment options for pancreatic ductal adenocarcinoma (PDAC) are limited. Histone deacetylase inhibitors are a new and promising drug family with strong anticancer activity. The aim of this study was to examine the efficacy of in vitro and in vivo treatment with the novel pan-HDAC inhibitor belinostat on the growth of human PDAC cells.

Methods: The proliferation of tumour cell lines (T3M4, AsPC-1 and Panc-1) was determined using an MTT assay.

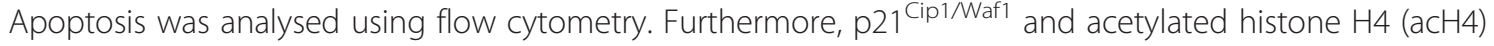
expression were confirmed by immunoblot analysis. The in vivo effect of belinostat was studied in a chimeric mouse model. Antitumoural activity was assessed by immunohistochemistry for Ki-67.

Results: Treatment with belinostat resulted in significant in vitro and in vivo growth inhibition of PDAC cells. This was associated with a dose-dependent induction of tumour cell apoptosis. The apoptotic effect of gemcitabine was further enhanced by belinostat. Moreover, treatment with belinostat increased expression of the cell cycle regulator p2 $1^{\text {Cip } 1 / \text { Waf1 }}$ in Panc-1, and of acH4 in all cell lines tested. The reductions in xenograft tumour volumes were associated with inhibition of cell proliferation.

Conclusion: Experimental treatment of human PDAC cells with belinostat is effective in vitro and in vivo and may enhance the efficacy of gemcitabine. A consecutive study of belinostat in pancreatic cancer patients alone, and in combination with gemcitabine, could further clarify these effects in the clinical setting.
\end{abstract}

Keywords: Pancreatic cancer, Histone deacetylase inhibitors, Belinostat, Mice

\section{Background}

Pancreatic ductal adenocarcinoma (PDAC) is a highly aggressive gastrointestinal tumour. It represents the fourth leading cause of cancer related deaths in both males and females in the western world [1]. Its resistance to most forms of therapy such as chemo-, radio-, immuno-, or targeted therapy contributes to the high mortality of this malignancy [2]. Curative resection is the only option to achieve long-term survival, but can be performed in only $15-20 \%$ of newly diagnosed pancreatic cancer patients [3].

\footnotetext{
* Correspondence: jens.werner@med.uni-heidelberg.de

${ }^{1}$ Department of General Surgery, University of Heidelberg, Im Neuenheimer Feld 110, 69120, Heidelberg, Germany

Full list of author information is available at the end of the article
}

Despite numerous findings that have contributed to the understanding [4] of PDAC pathogenesis, the reasons for its aggressive biological behaviour remain unclear. Therefore, new drugs for pancreatic adenocarcinoma are urgently needed. One of the most encouraging fields in modern oncological research is the investigation of epigenetics. Histone deacetylase inhibitors (HDACi) are typical representatives of this field of research, and may serve as promising agents with strong anticancer activity. The mechanism of HDACi activity is remodelling of chromatin through a modification of histone molecules, with consecutive initiation of cell differentiation, cellcycle arrest and induction of apoptosis. Additionally, HDACi might affect neoplastic growth by regulating host immune responses and tumour vasculature [5]. Clinical studies have shown that HDACi can be administered 
safely in humans, and that treatment with these agents seems to be beneficial for some types of cancers $[6,7]$.

A new hydroxamate type HDACi, belinostat (previously called PXD101), has been shown to be a potent anti-tumour agent with sub- to low micromolar IC50 potency in several tumour cell lines. In animal studies, belinostat specifically inhibited tumour growth at nontoxic concentrations $[8,9]$. Moreover, this compound has recently been evaluated in clinical phase I and II studies in both haematological and solid malignancies $[10,11]$. However, its efficacy in pancreatic cancer is unknown. Therefore, the aim of this study was to examine the efficacy of the novel pan-HDAC inhibitor belinostat on the growth of human PDAC cells in vitro and in vivo.

\section{Methods}

\section{Cell culture and treatment}

PDAC cell lines Panc-1 and AsPC-1 were obtained from the American Type Culture Collection (Manassas, VA, USA). T3M4 was a gift from R.S. Metzgar (Duke University, NC, USA). Cells were cultured in RPMI 1640 medium supplemented with $10 \%$ foetal bovine serum (FBS), $100 \mathrm{U} / \mathrm{ml}$ penicillin, and $100 \mu \mathrm{g} / \mathrm{ml}$ streptomycin (Invitrogen $\mathrm{GmbH}$, Karlsruhe, Germany) at $37{ }^{\circ} \mathrm{C}$ in a humidified $5 \% \mathrm{CO}_{2}$ atmosphere. When cells were subconfluent, medium was changed on both untreated and treated cells. Cells were treated with defined concentrations of a belinostat (Topotarget, København, Denmark) stock dissolved in DMSO. Control cells were grown following a similar protocol in medium supplemented with equivalent volumes of PBS.

\section{MTT assay for cell proliferation}

A 3-(4,5-dimethylthiazol-2-yl)-2.5-diphenyltetrazoliumbromide (MTT) (Sigma-Aldrich Chemie, Steinheim, Germany) assay was used to assess cell proliferation reflected by metabolic activity of the cells. The cells were seeded in 96-well plates at a density of 5000 cells/well in $250 \mu \mathrm{l}$ of complete medium. After the cells became adherent (in $24 \mathrm{~h}$ ), they were exposed to belinostat ( $25 \mathrm{nM}$, $50 \mathrm{nM}, 100 \mathrm{nM}, 300 \mathrm{nM}, 500 \mathrm{nM}, 800 \mathrm{nM}$, or $1000 \mathrm{nM}$ ) for $48 \mathrm{~h}$. Cells exposed to PBS served as controls. After the indicated times, $10 \mu \mathrm{l}$ of MTT $(5 \mathrm{mg} / \mathrm{ml}$, dissolved in PBS, $\mathrm{pH}$ 7.4) were added to each well and incubated for $4 \mathrm{~h}$. After incubation, the culture medium was aspirated and the plates were dried by inversion for about $15 \mathrm{~min}$. Subsequently, the formazan products were solubilised with acidic isopropanol $(100 \mu \mathrm{l}$ for each well) and the optical density was measured at $\lambda=570 \mathrm{~nm}$ with a Multiscan EX plate reader (Thermo Electron). All assays were performed in triplicate. Proliferation in the control group was set as $100 \%$.

\section{Immunoblotting}

After $24 \mathrm{~h}$ treatment with Belinostat (100 nM for T3M4 and ASPC or $300 \mathrm{nM}$ for Panc-1), cells were washed twice with ice cold PBS before lysis with SDS lysis buffer (2\% w/w SDS, $1 \mathrm{mM} \mathrm{DTT,} \mathrm{10 \%} \mathrm{v/v} \mathrm{Glycerol,} 62.5 \mathrm{mM}$ Tris- $\mathrm{HCl} \mathrm{pH} 6.8,0.05 \% \mathrm{w} / \mathrm{v}$ Bromphenolblue). Protein concentration was determined by BCA protein assay (Pierce Chemical Co., Rockford, IL, USA). Cell lysates (30 $\mu \mathrm{g}$ protein/lane) were separated on a $15 \% \mathrm{SDS} /$ polyacrylamide gel and electroblotted on PVDF membrane (Whatman, Maidstone, UK). Membranes were then incubated in blocking solution (5\% milk in $20 \mathrm{mM}$ Tris$\mathrm{HCl}, 150 \mathrm{mM} \mathrm{NaCl}, 0.1 \%$ Tween-20), followed by overnight incubation at $4{ }^{\circ} \mathrm{C}$ with anti acH4, CHIP-Grade antibody (Upstate Biotechnology, Billerica, USA) at a dilution of 1:75,000, or rabbit polyclonal anti- p21 $1^{\text {Cip1/Waf1 }}$ (Abcam, Cambridge, UK) at a 1:200 dilution. The membranes were then washed in TTBS and incubated with secondary antibodies: POD conjugated donkey antirabbit (Promega, Mannheim, Germany) at 1:150,000 dilution (blot for acH4) or POD conjugated goat antirabbit IgG (GE Healthcare Limited, Buckinghamshire, UK) at 1:2000 dilution (blot for $\mathrm{p}^{\text {Cip1/Waf1 }}$ ).

Antibody detection was performed using an enhanced chemiluminescence reaction (Amersham Bioscience). Equal lane loading was confirmed using anti-actin (Clone AC-15) antibody (Sigma-Aldrich Chemie). The actin signal obtained after incubation with anti-actin antibody on the same membrane was used as an internal control, in addition to loading all lanes with the same amount $(30 \mu \mathrm{g})$ of protein. All assays were performed in triplicate. For the semiquantitative analysis of the immunoblots, densitometry using the ImageJ program was carried out, and the signal intensity of acH4 or $\mathrm{p} 21^{\text {Cip1/Waf1 }}$ expression was normalised to its corresponding signal intensity of actin.

\section{Induction and analysis of cell death by flow cytometry}

Belinostat was diluted in phosphate-buffered saline (PBS) to a final concentration ranging from 100 to 1000 $\mathrm{nM}$, according to the concentrations indicated in each experiment. Gemcitabine (Synchem OHG, Felsberg, Altenburg, Germany) was applied at a final concentration of $0.01 \mathrm{mM}$ in PBS. All cells were treated and cultivated under the same conditions $\left(37^{\circ} \mathrm{C}\right.$ with $5 \% \mathrm{CO} 2$ in RPMI 1640), and exposed to the drugs $24 \mathrm{~h}$ before the experiments.

The viability of PDAC cells after exposure to belinostat and/or gemcitabine was analysed using annexin V/propidium iodide (PI)-staining (Annexin V-FITC Apoptosis Detection Kit I, BD Biosciences, Heidelberg, Germany). This method allows discrimination between early (annexin V+/PI-) and late (annexin $\mathrm{V}+/ \mathrm{PI}+$ ) apoptotic, as well as necrotic (annexin $\mathrm{V}-/ \mathrm{PI}+$ ) and viable (annexin 
V-/PI-) cells. The staining was performed according to the manufacturer's instructions. Briefly, the cells were suspended in a buffer solution $(10 \mathrm{mM}$ Hepes $/ \mathrm{NaOH}$ at $\mathrm{pH}$ 7.4, $140 \mathrm{mM} \mathrm{NaCl}, 2.5 \mathrm{mM} \mathrm{CaCl}$ ) at a final concentration of $1 \times 10^{6}$ cells $/ \mathrm{ml}$. After addition of Annexin V-FITC, the cells were incubated for $15 \mathrm{~min}$ at room temperature without light exposure. Flow cytometry was performed using the FACS LSR II system (BD Biosciences). A total of 10,000 ungated events were acquired for each sample, and data were analysed with the BD FACS Diva ${ }^{\circledR}$ with the CSD module (BD Biosciences). In order to determine late apoptotic cells, PI was added to the samples. Flow cytometry was performed immediately thereafter.

\section{In vivo tumourigenicity study}

A total of 300,000 T3M4 cells in $200 \mu \mathrm{l}$ RPMI 1640 medium were injected subcutaneously behind the anterior forelimb of four-week-old athymic mice through a 26-gauge needle. The injection sites were examined daily for the appearance of tumours. Treatment was started on the seventh day after tumour inoculation. Mice were divided into groups receiving belinostat $(0.1 \mathrm{mg} / \mathrm{g}$, $5 \times$ weekly), gemcitabine $(0.15 \mathrm{mg} / \mathrm{g}, 2 \times$ weekly $)$, or a combination of both (Belinostat at $0.1 \mathrm{mg} / \mathrm{g}, 5 \times$ weekly, plus gemcitabine at $0.15 \mathrm{mg} / \mathrm{g}, 2 \times$ weekly) i.p., whereas the control group (sham) received only PBS $(20 \mu \mathrm{l} / \mathrm{g}$,
$5 \times$ weekly). Treatment was continued for 28 consecutive days, and tumours were measured twice weekly with Vernier callipers. Tumour volumes were calculated using the formula: tumour volume $=\left(\mathrm{L} \times \mathrm{W}^{2}\right) / 2$, with $\mathrm{L}$ representing the length and $\mathrm{W}$ the width of the tumour [12].

The same treatment was performed after tumour inoculation by direct injection in the pancreatic tail via laparotomy. In this case, the tumours were compared at the end of 28- days of treatment.

After completion of treatment, the animals were sacrificed, and tumours were excised, fixed, and embedded in paraffin. The numbers of mice in each treatment cohort was 6. All experiments on animals were approved in accordance with German law on the care and use of laboratory animals.

\section{Immunohistochemistry}

Paraffin-embedded tissue sections (2-3 mm thick) were deparaffinised in xylene and rehydrated in progressively decreasing concentrations of ethanol. Thereafter, slides were placed in washing buffer. Antigen retrieval was carried out by microwaving the tissue sections in $10 \mathrm{mM}$ citrate buffer for $10 \mathrm{~min}$. Sections were then incubated first with normal goat serum (DAKO Corporation, Carpinteria, CA, USA) for $45 \mathrm{~min}$ to block non-specificbinding sites, and then with a mouse monoclonal Ki-67
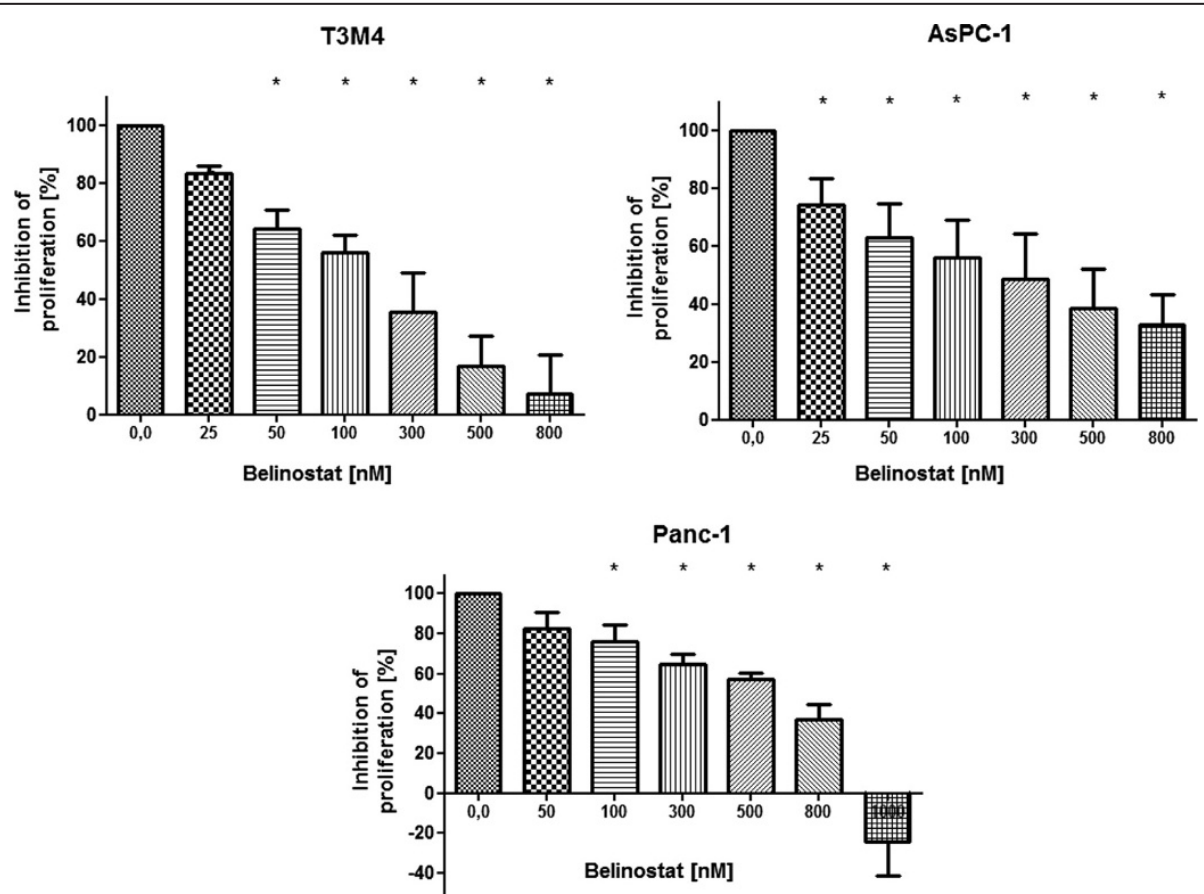

Figure 1 Proliferation of PDAC cells (MTT assay). Treatment with belinostat reduces the proliferation of pancreatic carcinoma cell lines in vitro in a dose-dependent manner. T3M4, AsPC-1 and Panc-1 cells were cultivated with increasing concentrations of belinostat. After $48 \mathrm{~h}$, cell viability was determined. Data are presented as mean \pm SEM. ${ }^{*} p<0.05$ vs. control. 
antibody, diluted 1:5 (DAKO Corporation). Incubation was performed for $18 \mathrm{~h}$ at $4{ }^{\circ} \mathrm{C}$. Slides were then rinsed in washing buffer and incubated with a biotinylated secondary goat anti-mouse antibody (DAKO Corporation) for $45 \mathrm{~min}$ at room temperature. The slides were then washed in washing buffer, and each section was exposed to $100 \mu \mathrm{l}$ DAB-chromogen substrate mixture (DAKO Corporation), then counterstained with Mayer's haematoxylin. The sections were washed again, dehydrated in increasing concentrations of ethanol, and mounted with xylene-based mounting medium. Every staining was controlled with a negative control. For semi-quantitative analysis, slides were scored in a blinded manner by two observers. Using 400-fold image magnification, the positive and negative stained cells were counted at three independent units area. Next, the percentage of the positive stained cells was calculated.

\section{Statistical analysis}

Results are expressed as mean \pm standard error of the mean (SEM). Analysis of variance (ANOVA) was used to show an overall difference between groups, the Student $t$ test for pairwise comparison of normal distributed parameters, and the Mann-Whitney $U$ test for parameters without normal distribution. Significance was defined as $p<0.05$. Graphical presentations were performed using GraphPad Prism version 4.02 for Windows (GraphPad Software).

\section{Results}

\section{Effects of belinostat in vitro}

Antiproliferative effect of belinostat on pancreatic cancer cells

Belinostat caused a significant dose-dependent decrease in cell proliferation in all cell lines tested. The ED50
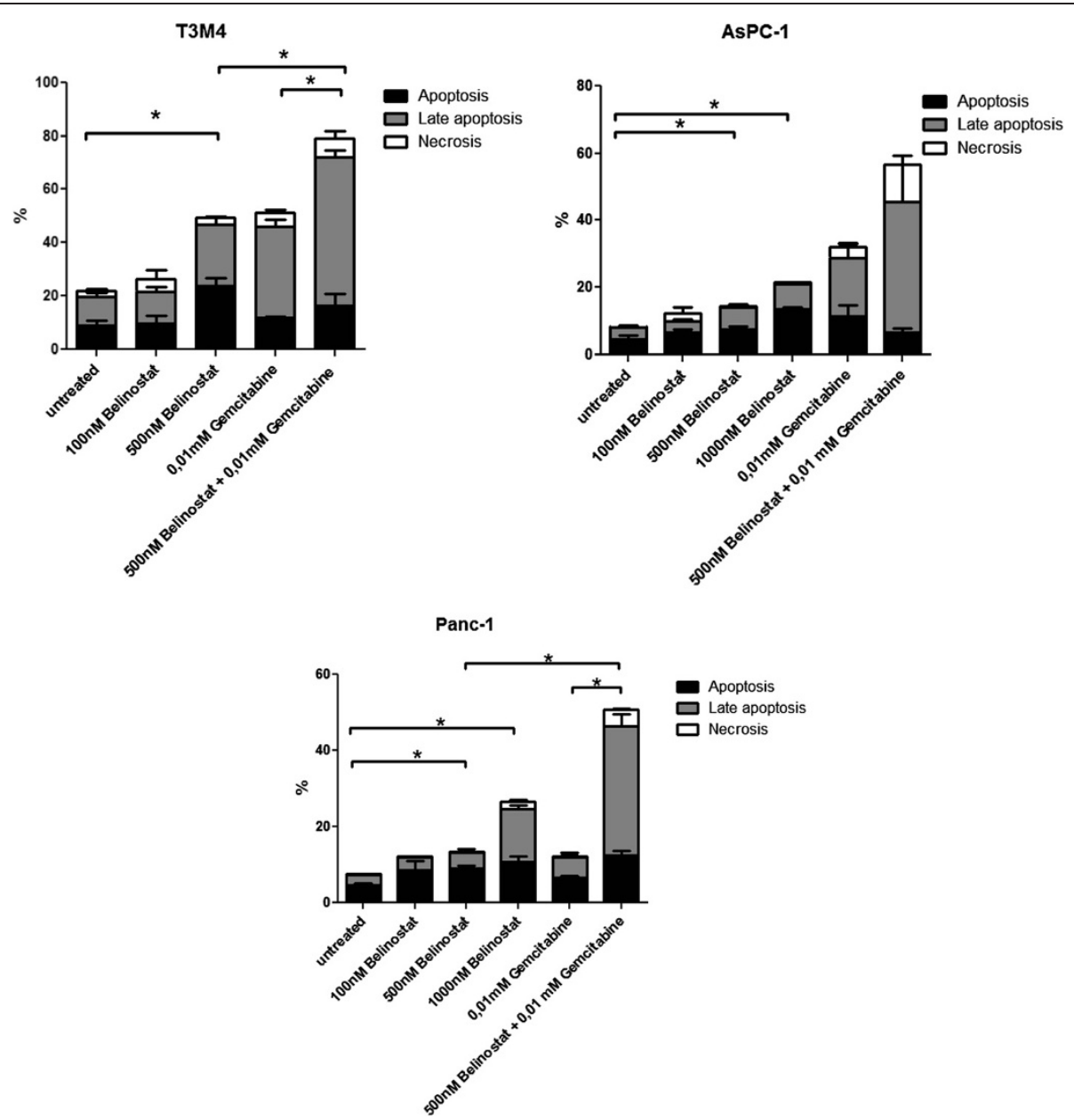

Figure 2 Apoptosis and necrosis in PDAC cell lines after treatment with belinostat and (or) gemcitabine. The percentage of dying tumour cells after treatment with belinostat, gemcitabine or belinostat + gemcitabine, stratified into early apoptotic, late apoptotic and necrotic fractions in the different PDAC cell lines. Belinostat increased apoptosis in a dose-dependent fashion in T3M4, AsPC-1 and Panc-1 cell lines. Moreover, the combination of belinostat and gemcitabine significantly enhanced apoptosis in T3M4 and Panc-1. Data are presented as mean \pm SEM. ${ }^{*} p<0.05$ vs. control. 
concentrations for belinostat were $\sim 100 \mathrm{nM}$ for T3M4, $\sim 200 \mathrm{nM}$ for AsPC-1 and $\sim 600 \mathrm{nM}$ for Panc-1 (Figure 1).

\section{Apoptosis induction in pancreatic cancer cells by belinostat treatment}

As shown in Figure 2, treatment with belinostat induced dose dependent apoptosis in all cell lines tested. The differences compared to control were significant at concentrations of $500 \mathrm{nM}$ or more in all cell lines tested.

\section{Belinostat increases gemcitabine-mediated apoptosis in pancreatic tumour cells}

When concomitant use of both drugs (500 nM belinostat and 0,01 mM gemcitabine) was tested in T3M4, AsPC-1 and Panc- 1 cells, the combined treatment significantly enhanced the proapoptotic activity compared to gemcitabine treatment alone in Panc-1 ( 3 fold) and T3M4 ( 1.5 fold) cells (Figure 2).

\section{Inhibition of histone deacetylation after belinostat treatment}

In Western Blot analysis with an anti-ac-histone $\mathrm{H} 4$ antibody, treatment with belinostat significantly increased acetylation of histone 4 in all cell lines tested (Figure 3A).

\section{Belinostat induces expression of $p 21^{\text {Cip 1/Waf1 }}$}

In addition, belinostat was effective in increasing the level of $\mathrm{p} 21^{\text {Cip1/Waf1 }}$, which is related to HDACi-induced growth arrest in pancreatic carcinoma cells. Figure 3B demonstrates the increased expression of $\mathrm{p} 21^{\text {Cip } 1 / \text { Waf1 }}$ after belinostat treatment in Panc-1 cells.

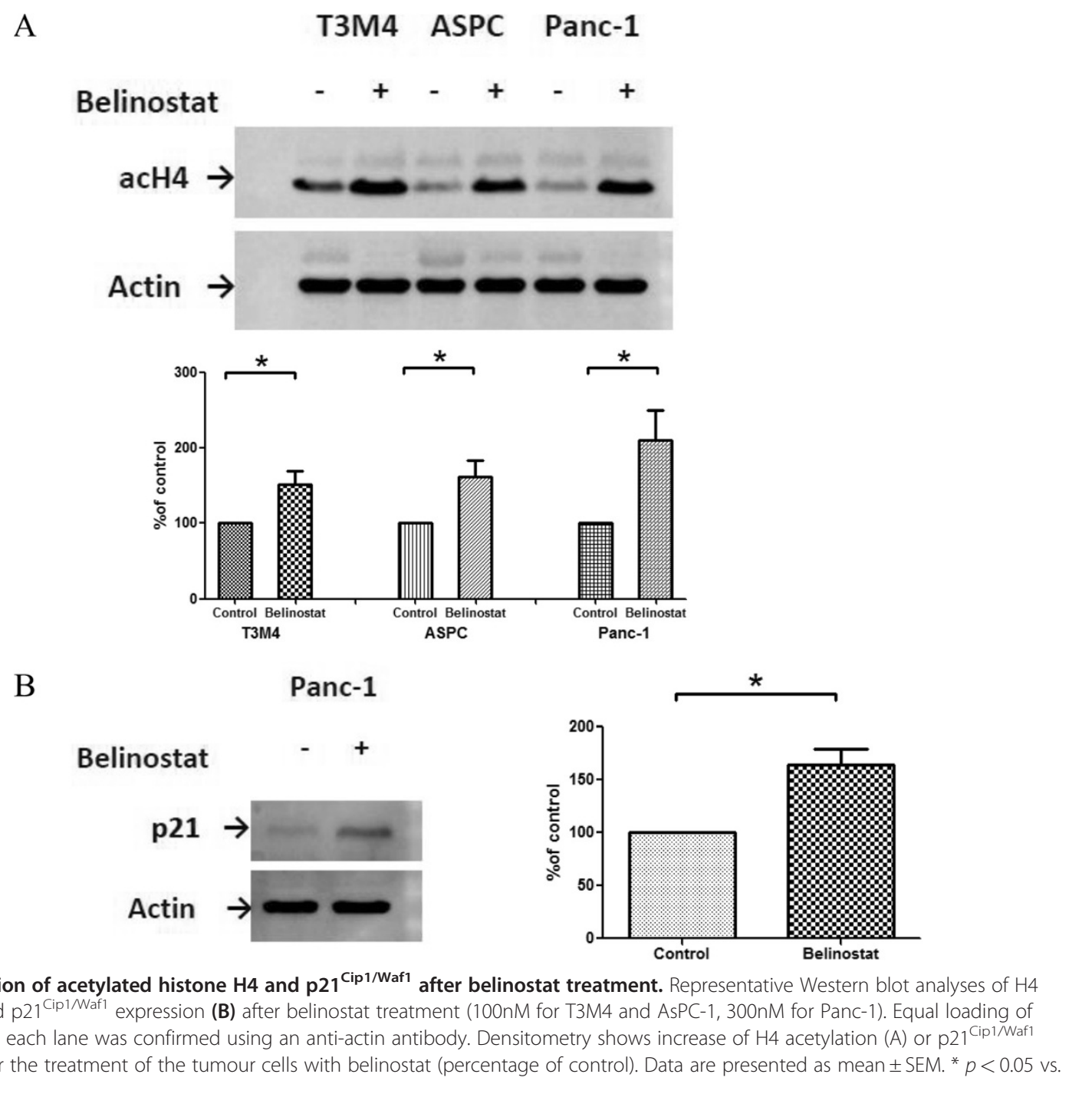


Inhibition of in vivo tumour growth by belinostat

Tumours in the belinostat treatment group showed significantly reduced growth in both subcutaneous and intrapancreatic tumours compared with the control group, in in vivo experiments (Figures $4 \mathrm{~A}$ and $\mathrm{B}$ ). The combination of belinostat and gemcitabine therapy showed no additional growth inhibition.

Routine hematoxylin/eosin histological examination showed no morphological differences between the tumours in the treatment and control groups. However, analysis of their proliferation rates (Figure 5) using an anti-Ki-67 antibody, showed a significantly lower number of proliferating cells per unit area in the belinostat group (47.8 \pm 5.7 cells per high-power field) compared with the control group $(79.1 \pm 2.2)$.

\section{Discussion}

PDAC remains a therapeutic challenge with a poor overall prognosis. Only surgery with adjuvant chemotherapy can achieve a long-term perspective in patients with localized
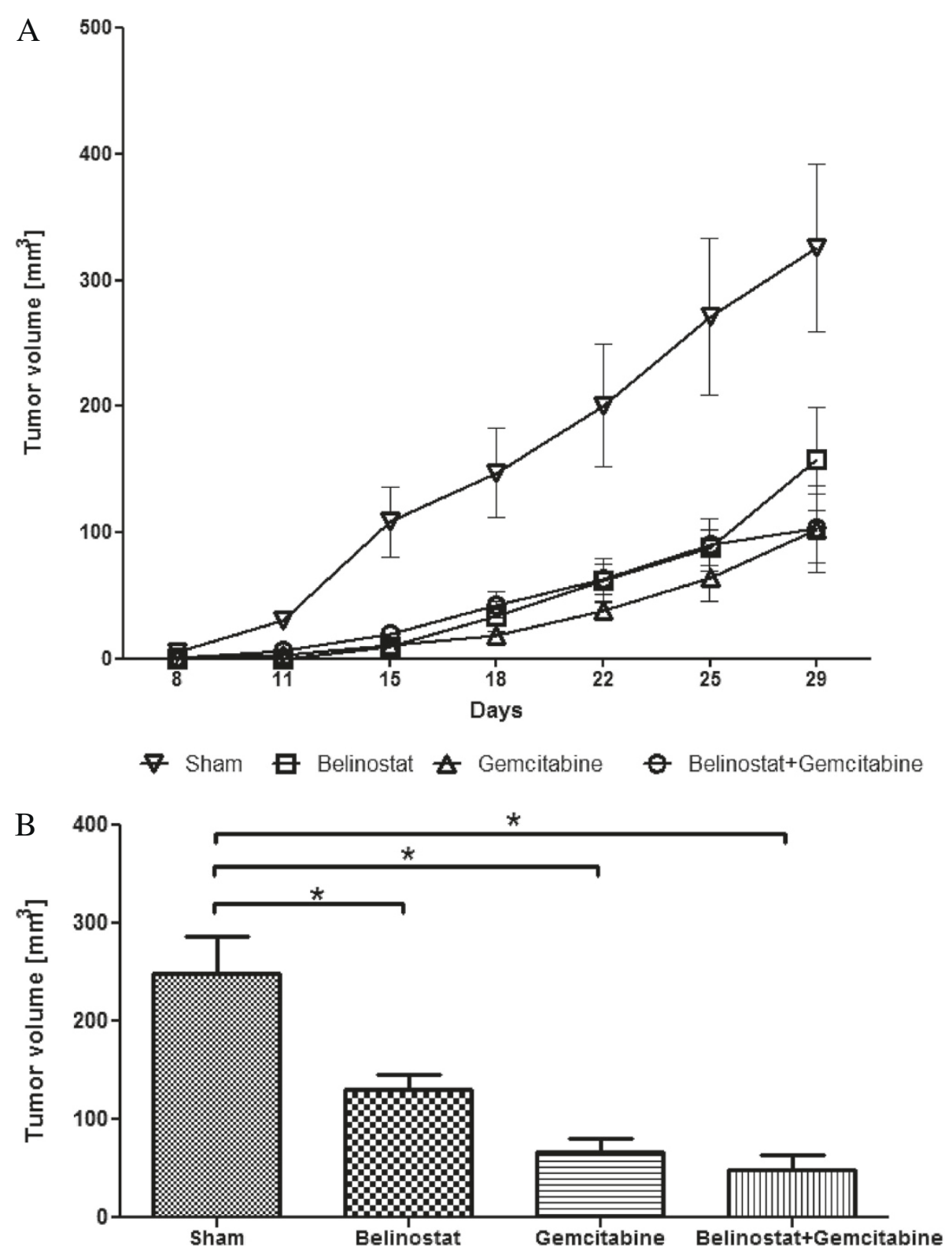

Figure 4 Growth inhibition of xenograft tumours. Subcutaneous (A) and intrapancreatic (B) xenograft tumour growth of T3M4 cells in nude mice treated with PBS (sham), belinostat, gemcitabine or belinostat + gemcitabine. The mean of the tumour volume was calculated from measurable tumours at each time point. In summary, tumours in the treatment groups were smaller compared to sham. The differences between the treatment groups were not significant. Data are presented as mean \pm SEM. ${ }^{*} p<0.05$. 


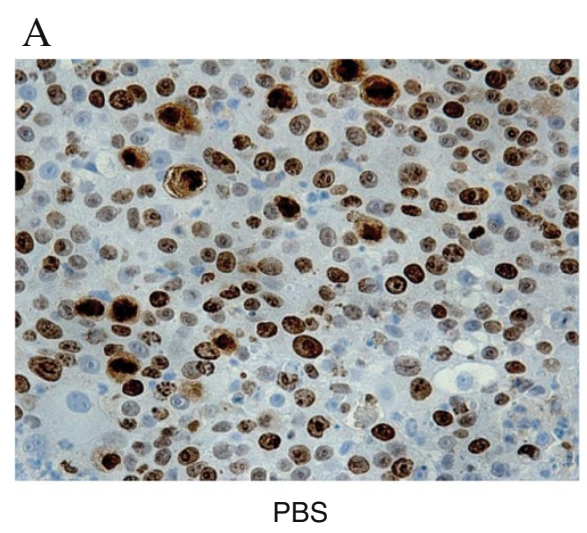

PBS

\section{B}

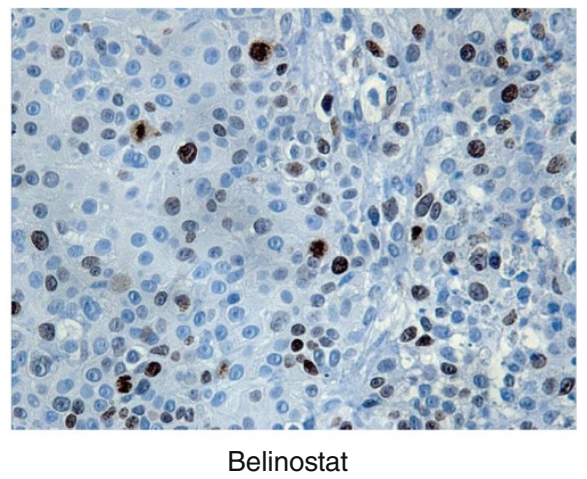

C

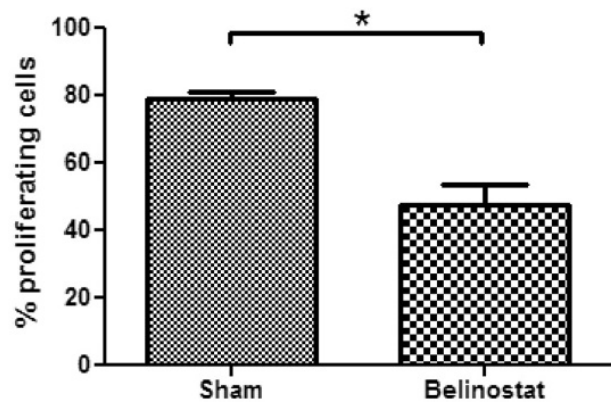

Figure 5 Immunohistochemical analysis of cell proliferation in xenograft tumours. Proliferating cells in sham (A) and belinostat (B) groups as assessed by an anti-Ki-67 antibody. The pictures were taken at 400-fold magnification. (C) Treatment with Belinostat led to a significant decrease in proliferating cells. Data (\% proliferating cells per unit area) are presented as mean \pm SEM. ${ }^{*} p<0.05$.

tumours [13-15]. Adjuvant postoperative chemotherapy based on 5-FU or gemcitabine has been shown to improve the survival of these patients [16]. However, even under optimal treatment conditions, the 5-year survival rate doesn't exceed 25\% [13]. Additionally, palliative treatment in advanced tumour stages is associated with a poor prognosis and a median survival of about 6 months. To improve this situation, investigation of new therapeutic agents for PDAC treatment is essential.

The family of HDACi represents a novel approach in oncological research. In defined - predominantly haematological - tumour entities, HDACi have already passed the stage of experimental research and been investigated clinically [17]. Regarding PDAC, promising results have been shown using SAHA, TSA, butyrate and some other histone deacetylase inhibitors in experimental studies $[6,18-20]$. Belinostat is a novel member of the family with a distinct pan-HDAC inhibitory effect. It has been shown to be strongly effective in experimental settings of ovarian, bladder and colon cancer, as well as haematological tumour entities [9,21-24]. Consecutive clinical trials have proven an anti-tumour effect of belinostat as a monotherapy in T-cell lymphomas and thymomas. In addition, belinostat has demonstrated beneficial effects in combination with other anti-cancer drugs for the treatment of ovarian and bladder cancer, CUP, multiple myeloma and acute myeloid leukaemia. Despite these findings, no data are available concerning belinostat in the context of PDAC treatment. Consequently, in the present study, the efficacy of belinostat for PDAC treatment was investigated in experimental in vitro and in vivo settings for the first time.

Comparable to the results of previous studies in bladder [8], colorectal [25] or hepatocellular carcinoma [21], we found a strong dose dependent antiproliferative activity of belinostat in three pancreatic cancer cell lines (T3M4, Panc-1 and AsPC-1) with an IC50 concentration in the nanomolar range, similar to other tumour entities $[8,25]$.

This antiproliferative effect can be explained by a strong proapoptotic activity in pancreatic cancer cells, demonstrated by annexinV/propidium iodide staining. This is in line with other studies on AML- [26] and hepatocellular carcinoma cells [21], underlining that apoptosis induction is an important mechanism of the anti-tumourous effect of $\mathrm{HDACi}$, and particularly belinostat. As apoptosis induction is an important mechanism of anti-cancer chemotherapy [27], we tested the 
influence of concomitant use of belinostat and gemcitabine. As described in studies with other HDACi like trichostatin A [6] and 4-phenylbutyrate [18], the combination of gemcitabine and belinostat strongly enhanced the proapoptotic effects of each substance alone. This may be due to the expression of proapoptotic proteins like Caspase- 8 and Bid, and activation of the gemcitabine-mediated JNK-pathway [18].

Increase in histone $\mathrm{H} 4$ acetylation has been shown to be helpful in monitoring belinostat activity [28]. Consequently, we examined belinostat-dependent expression of acH4 in PDAC cells. Acetylation of $\mathrm{H} 4$ was increased in all cell lines tested, confirming the inhibitory effect of belinostat on HDAC activity in pancreatic cancer cells.

Cyclin-dependent kinase inhibitor p21 ${ }^{\text {Cip1/Waf1 }}$ is a key protein participating in cell cycle regulation. Previous studies have shown that HDACi activates expression of p21 ${ }^{\text {Cip1/Waf1 }}$ through enhanced histone acetylation around the $\mathrm{p} 21^{\mathrm{Cip} 1 / \mathrm{Waf1}}$ promoter [29]. We performed western blot analysis with treated and control Panc- 1 cells to clarify the effect of belinostat on p21 ${ }^{\text {Cip1/Waf1 }}$ expression. Belinostat induced an upregulation of $\mathrm{p}^{\mathrm{Cip} 1 / \mathrm{Waf} 1}$, as has been described for other HDAC inhibitors in pancreatic cancer $[18,30]$. Increased expression of $\mathrm{p} 21^{\text {Cip1/Waf1 }}$ in these studies was associated with normalization of the cell cycle and induction of apoptosis.

Regarding the effect of belinostat in vivo, we observed that belinostat was an effective growth inhibitor of T3M4 pancreatic cancer cells in a nude mouse model. Mice treated with belinostat showed xenograft growth inhibition for more than 28 days after tumour inoculation, without any signs of toxicity. The reduction in the tumour volume was associated with decreased cell proliferation, as shown by Ki-67 immunohistochemistry. Similar observations in in vivo tumour models were shown in previous studies, e.g. in human ovarian cancer s.c. xenografts; the efficacy of the treatment with belinostat was further enhanced when a combination therapy with carboplatin was added [24]. Plumb et al. [22] described a significant dose-dependent growth delay of human colon tumour xenografts in mice after belinostat treatment, without signs of toxicity.

In contrast to our in vitro observations, we could not find an additional effect of combined therapy with belinostat and gemcitabine in vivo. A possible explanation for this discrepancy is the relatively high dosage of gemcitabine administered in the in vivo study. This might have covered a possible additional belinostat effect.

\section{Conclusion}

In summary, this preclinical study using in vitro and in vivo pancreatic cancer models shows that belinostat is effective as a monotherapy of pancreatic cancer, primarily by inhibition of proliferation and induction of apoptosis.
In vitro results revealed that belinostat can be successfully combined with gemcitabine to potentiate induction of apoptosis in the tumour cells. These findings should be confirmed in the clinical setting in PDAC patients.

\section{Abbreviations}

HDAC: Histone deacetylase; HDACi: Histone deacetylase inhibitor; PDAC: Pancreatic ductal adenocarcinoma.

\section{Competing interests}

The authors declare that they have no competing interests.

\section{Author details}

${ }^{1}$ Department of General Surgery, University of Heidelberg, Im Neuenheimer Feld 110, 69120, Heidelberg, Germany. ${ }^{2}$ German Cancer Research Center (DKFZ), G340, Im Neuenheimer Feld 280, 69120, Heidelberg, Germany.

${ }^{3}$ Department of Pediatric Oncology, University of Heidelberg Medical Center, Im Neuenheimer Feld 430, 69120, Heidelberg, Germany.

\section{Authors' contributions}

DD conceived the study, participated in its design and coordination, and drafted the manuscript; SA carried out in vitro and in vivo studies with cell culture and performed immunohistochemistry; TH participated in the study design and helped to draft the manuscript; $1 O$ performed immunoblot analysis; OW, KF and NG participated in the design of the study and revised the manuscript; JW participated in the overall design and study coordination, and finalized the draft of the manuscript. All authors read and approved the final manuscript

Received: 10 January 2012 Accepted: 8 June 2012

Published: 8 June 2012

\section{References}

1. Jemal A, Siegel R, Xu J, Ward E: Cancer statistics. CA Cancer J Clin 2010, 60(5):277-300.

2. Li D, Xie K, Wolff R, Abbruzzese JL: Pancreatic cancer. Lancet 2004, 363(9414):1049-1057.

3. Lockhart AC, Rothenberg ML, Berlin JD: Treatment for pancreatic cancer: current therapy and continued progress. Gastroenterology 2005 , 128(6):1642-1654.

4. Welsch T, Kleeff J, Friess H: Molecular pathogenesis of pancreatic cancer: advances and challenges. Curr Mol Med 2007, 7(5):504-521.

5. Bolden JE JPM, JR W: Anticancer activities of histone deacetylase inhibitors. NATURE REVIEWS 2006, 5:769-784.

6. Donadelli M, Costanzo C, Beghelli S, Scupoli MT, Dandrea M, Bonora A, Piacentini P, Budillon A, Caraglia M, Scarpa A, et al: Synergistic inhibition of pancreatic adenocarcinoma cell growth by trichostatin $A$ and gemcitabine. Biochim Biophys Acta 2007, 1773(7):1095-1106.

7. Kouraklis $\mathrm{G}$, Theocharis $\mathrm{S}$ : Histone deacetylase inhibitors: a novel target of anticancer therapy (review). Oncol Rep 2006, 15(2):489-494.

8. Buckley MT, Yoon J, Yee H, Chiriboga L, Liebes L, Ara G, Qian X, Bajorin DF, Sun TT, Wu XR, et al: The histone deacetylase inhibitor belinostat (PXD101) suppresses bladder cancer cell growth in vitro and in vivo. J Transl Med 2007, 5:49.

9. Tumber A, Collins LS, Petersen KD, Thougaard A, Christiansen SJ, Dejligbjerg $M$, Jensen PB, Sehested M, Ritchie JW: The histone deacetylase inhibitor PXD101 synergises with 5-fluorouracil to inhibit colon cancer cell growth in vitro and in vivo. Cancer Chemother Pharmacol 2007, 60(2):275-283.

10. Giaccone G, Rajan A, Berman A, Kelly RJ, Szabo E, Lopez-Chavez A, Trepel J, Lee MJ, Cao L, Espinoza-Delgado I, et al: Phase II study of belinostat in patients with recurrent or refractory advanced thymic epithelial tumors. J Clin Oncol 2011, 292(15):052-2059.

11. Gimsing P, Hansen M, Knudsen LM, Knoblauch P, Christensen IJ, Ooi CE, Buhl-Jensen P: A phase I clinical trial of the histone deacetylase inhibitor belinostat in patients with advanced hematological neoplasia. Eur J Haematol 2008, 81(3):170-176.

12. Sanchez $Y$, el-Naggar A, Pathak S, Killary AM: A tumor suppressor locus within 3p14-p12 mediates rapid cell death of renal cell carcinoma in vivo. Proc Natl Acad Sci U S A 1994, 91(8):3383-3387. 
13. Neoptolemos JP, Stocken DD, Bassi C, Ghaneh P, Cunningham D, Goldstein D, Padbury R, Moore MJ, Gallinger S, Mariette C, et al: Adjuvant chemotherapy with fluorouracil plus folinic acid vs gemcitabine following pancreatic cancer resection: a randomized controlled trial. Jama 2010, 304(10):1073-1081.

14. Neoptolemos JP, Stocken DD, Tudur Smith C, Bassi C, Ghaneh P, Owen E, Moore M, Padbury R, Doi R, Smith D, et al: Adjuvant 5-fluorouracil and folinic acid vs observation for pancreatic cancer: composite data from the ESPAC1 and -3(v1) trials. British journal of cancer 2009, 100(2):246-250.

15. Oettle H, Post S, Neuhaus P, Gellert K, Langrehr J, Ridwelski K, Schramm H, Fahlke J, Zuelke C, Burkart C, et al: Adjuvant chemotherapy with gemcitabine vs observation in patients undergoing curative-intent resection of pancreatic cancer: a randomized controlled trial. Jama 2007, 297(3):267-277.

16. Cunningham D, Chau I, Stocken DD, Valle JW, Smith D, Steward W, Harper PG, Dunn J, Tudur-Smith C, West J, et al: Phase III randomized comparison of gemcitabine versus gemcitabine plus capecitabine in patients with advanced pancreatic cancer. J Clin Oncol 2009, 27(33):5513-5518.

17. Bolden JE, Peart MJ, Johnstone RW: Anticancer activities of histone deacetylase inhibitors. Nat Rev Drug Discov 2006, 5(9):769-784.

18. Ammerpohl O, Trauzold A, Schniewind B, Griep U, Pilarsky C, Grutzmann R, Saeger HD, Janssen O, Sipos B, Kloppel G, et al: Complementary effects of HDAC inhibitor 4-PB on gap junction communication and cellular export mechanisms support restoration of chemosensitivity of PDAC cells. Br J Cancer 2007, 96(1):73-81.

19. Haefner M, Bluethner T, Niederhagen M, Moebius C, Wittekind C, Mossner J, Caca K, Wiedmann M: Experimental treatment of pancreatic cancer with two novel histone deacetylase inhibitors. World J Gastroenterol 2008, 14(23):3681-3692.

20. Kumagai T, Wakimoto N, Yin D, Gery S, Kawamata N, Takai N, Komatsu N, Chumakov A, Imai Y, Koeffler HP: Histone deacetylase inhibitor, suberoylanilide hydroxamic acid (Vorinostat, SAHA) profoundly inhibits the growth of human pancreatic cancer cells. Int I Cancer 2007, 121(3):656-665.

21. Ma BB, Sung F, Tao Q, Poon FF, Lui WW, Yeo W, Chan SL, Chan AT: The preclinical activity of the histone deacetylase inhibitor PXD101 (belinostat) in hepatocellular carcinoma cell lines. Invest New Drugs 2008, 28(2):107-114

22. Plumb JA, Finn PW, Williams RJ, Bandara MJ, Romero MR, Watkins CJ, La Thangue NB, Brown R: Pharmacodynamic response and inhibition of growth of human tumor xenografts by the novel histone deacetylase inhibitor PXD101. Mol Cancer Ther 2003, 2(8):721-728.

23. Qian X, Ara G, Mills E, LaRochelle WJ, Lichenstein HS, Jeffers M: Activity of the histone deacetylase inhibitor belinostat (PXD101) in preclinical models of prostate cancer. Int J Cancer 2008, 122(6):1400-1410.

24. Qian X, LaRochelle WJ, Ara G, Wu F, Petersen KD, Thougaard A, Sehested M, Lichenstein HS, Jeffers M: Activity of PXD101, a histone deacetylase inhibitor, in preclinical ovarian cancer studies. Mol Cancer Ther 2006, 5(8):2086-2095.

25. Kim JC, Kim DD, Lee YM, Kim TW, Cho DH, Kim MB, Ro SG, Kim SY, Kim YS, Lee JS: Evaluation of novel histone deacetylase inhibitors as therapeutic agents for colorectal adenocarcinomas compared to established regimens with the histoculture drug response assay. Int I Colorectal Dis 2009, 24(2):209-218.

26. Stapnes C, Ryningen A, Hatfield K, Oyan AM, Eide GE, Corbascio M, Kalland $\mathrm{KH}$, Gjertsen BT, Bruserud O: Functional characteristics and gene expression profiles of primary acute myeloid leukaemia cells identify patient subgroups that differ in susceptibility to histone deacetylase inhibitors. Int J Oncol 2007, 31(6):1529-1538.

27. Bold RJ, Chandra J, McConkey DJ: Gemcitabine-induced programmed cell death (apoptosis) of human pancreatic carcinoma is determined by Bcl-2 content. Ann Surg Oncol 1999, 6(3):279-285.

28. Marquard L, Petersen KD, Persson M, Hoff KD, Jensen PB, Sehested M: Monitoring the effect of belinostat in solid tumors by $\mathrm{H} 4$ acetylation. APMIS 2008, 116(5):382-392.

29. Ocker M, Schneider-Stock R: Histone deacetylase inhibitors: signalling towards p21cip1/waf1. Int J Biochem Cell Biol 2007, 39(7-8):1367-1374.

30. Arnold NB, Arkus N, Gunn J, Korc M: The histone deacetylase inhibitor suberoylanilide hydroxamic acid induces growth inhibition and enhances gemcitabine-induced cell death in pancreatic cancer. Clin Cancer Res 2007, 13(1):18-26. doi:10.1186/1471-2407-12-226

Cite this article as: Dovzhanskiy et al.: Experimental in vivo and in vitro treatment with a new histone deacetylase inhibitor belinostat inhibits the growth of pancreatic cancer. BMC Cancer 2012 12:226.

\section{Submit your next manuscript to BioMed Central and take full advantage of:}

- Convenient online submission

- Thorough peer review

- No space constraints or color figure charges

- Immediate publication on acceptance

- Inclusion in PubMed, CAS, Scopus and Google Scholar

- Research which is freely available for redistribution 